\title{
LACK OF LECTURER CLARITY DURING INSTRUCTION: POSSIBLE REASON FOR POOR THROUGHPUT?
}

\author{
M. H. Segabutla \\ Department of Applied Languages \\ Tshwane University of Technology \\ Pretoria, South Africa \\ e-mail: segabutlamh@tut.ac.za
}

\author{
R. Evans \\ Humanities Education Department \\ University of Pretoria \\ Pretoria, South Africa \\ e-mail: Rinelle.Evans@up.ac.za
}

\section{ABSTRACT}

In South Africa, students' academic success in tertiary environments is generally low, despite governmental or institutional interventions. Underpinned by McCroskey, Valencic and Richmond's (2004) General Model of Instructional Communication, we explored lecturer and student perceptions of lecturer clarity during instruction using a mixed-methods case study. A convenience sample of seven lecturers were interviewed and observed in situ. Questionnaires were completed by 252 first year students at a large South African university. Content and statistical data analyses revealed that a mismatch existed between lecturers' perceptions of their own instructional clarity and their students'. The high percentage of students who felt lost during a lecture suggests a high level of instructional dissonance, which might account for a less-than desirable academic throughput. We recommend that institutions quality assure lecturers' oral, written, content and process clarity prior to and during appointment.

Key words: English proficiency, instructional communication, instructional dissonance, lecturer clarity

\section{INTRODUCTION}

Concerns related to students not performing academically as expected remain at the forefront of South African higher education deliberations. Furthermore reports (Cosser and Letseka 2010; MacGregor 2009; Teven and Herring 2005) suggest that students are ill-equipped for the labour market. The South African government has attempted to address these concerns by introducing quality assurance systems, providing financial support, expecting institutions to introduce academic support programmes, and revise programme content; yet low throughput and poor retention rates remain. 
We approached this dilemma from an unchartered angle for the South African context; one not easily admitted but undeniably linked to academic success: the facilitator of content i.e. the lecturer. We asked to what degree the lecturer was perceived to provide clear instruction and although not measured, deduced what the possible implications of these perceptions are on student learning. Professionally, lecturers are expected to have mastered various teaching strategies, be knowledgeable about the content they teach, and be able to communicate this content clearly to their students, in order to facilitate behavioural, cognitive and psychomotor learning (Ferreira 2006; Worley et al. 2007; Haskins 2000). Several international studies (Finn and Schrodt 2012; Chesebro and McCroskey 2001) have been conducted on lecturers' instructional clarity and in South Africa, lecturer communication is also considered central to effective teaching and learning as borne out by Fraser and Killen (2005) who found that effective communication was a variable that influenced undergraduate pass rates at two universities. Studies by Wilson-Strydom (2015) and Lewin (2014) related to student access and success confirm that academic performance is poor at most South African universities and cite inadequate teaching as a contributing factors. Students' perceptions of those whom they regarded as competent, caring and trustworthy (Toale 2001) suggest that high clarity instructors produce more positive outcomes. Although investigating inadequate Grade 12 learner participation during interactive televised instruction, Evans (2006) found that technical and methodological design limitations were further complicated by presenters' ineffective communication skills. In this article, we explore the perceptions that participant lecturers had of their personal instructional clarity as well as students' perceptions of these lecturers' clarity during formal instruction. We later triangulated these perceptions with our in situ observations of the lecturers' communication behaviours. We explored this angle hoping to cast more light on the reasons for poor academic performance of students at tertiary institutions.

\section{CONTEXTUALISING LECTURER CLARITY}

We use the appellations "instructor" and "facilitator" when referring to someone who regardless of the teaching context - facilitates learning while in the South African milieu, "lecturer" refers to a person with advanced academic qualifications who teaches at a tertiary institution (Mothata et al. 2000).

Broadly speaking, lecturer clarity is a variable that implies the ability of an instructor to use both verbal and non-verbal messages appropriately to expound course content and thus stimulate the learning process (Chesebro and McCroskey 2001). It also refers to organising information so that it is comprehensible to students by repeating and rephrasing ideas, using examples and practical applications, or by emphasising main points (Rodger, Murray and 
Cummins 2007; Comadena, Hunt and Simonds 2007). Collins and O'Brien (2003, 65), in turn, define instructor clarity as a communication act in which "the exchange of ideas, including hearing or receiving information, speaking or sending information, and use of language, written, oral and symbolic" occur.

The aforementioned definitions are underpinned by two theories of instructor clarity; information processing, which views instructors as dispensers of information and students as information processors; and adaptive instruction which advocates that instructors need to adjust their instructional behaviours constantly as they communicate with their students (Titsworth and Mazer 2010). We thus view lecturer clarity as key to facilitating student learning and inadequate clarity could thus be responsible for the poor quality of a student's learning experience and inability to internalise content or master skills effectively. Our stance is closely linked to the process-product paradigm advocated by Gayle et al. (2009) who view teaching and learning as a rhetorical process in which the instructor's verbal and non-verbal messages influence the target audience i.e. the students. While we acknowledge that communication is a transactional process, as lecturers and students interact with each other to share knowledge and messages are exchanged between the lecturer and the students, the two models fell short in answering the research questions asked in our study.

Communication in the lecture hall is influenced by a number of instructional, linguistic, physical, psychological, and social factors, which are not evidenced in the two models. In addition, they exclude the students from taking responsibility for their own learning. More appropriate to our study is the General Model of Instructional Communication (GMIC) developed by McCroskey et al. (2004). This model evolved within the field of instructional communication (IC). Wrench, Peck and Gorham $(2009,4)$ define IC as "a process in which the teacher selects and arranges what the students are to learn (the content), decides how best to help them learn (the instructional strategy), determines how success in learning will be gauged and how students' progress will be communicated to them (evaluation/ feedback)". The model was designed based on the following components: an instructor's (non) verbal communication behaviours, source credibility, task attractiveness, instructional outcomes, students' temperaments, the instructional environment, and the focus of our study - lecturer clarity. We also included another component of the GMIC, which other models do not address i.e. students' perceptions of their lecturers' communication behaviours, when expounding new content. McCroskey et al. (2004) point out that in a classroom context, students form observational opinions of their lecturers even prior to being taught by that particular person. He adds that these perceptions may change as the course progresses and even after its completion, influencing their experiences, assumptions and knowledge acquisition. 
Lecturers who are rated highly in terms of their instructional clarity are known to produce more positive outcomes (Toale 2001), have a more favourable effect on students (Comadena, Hunt and Simonds 2007), and enhance students' apparent learning, making instructor clarity "additive" (Finn and Schrodt 2012). Therefore, clarity - along with enthusiasm, engagement and achieved outcomes - is considered one of the "four aces" of effective teaching (Bulger, Mohr and Wall 2002). Rodger, Murray, and Cummins (2007) also found a positive correlation between the effects of high versus low lecturer clarity on both student achievement and motivation with probable positive effects on affective learning. Sidelinger and McCroskey (1997) further purport that as instructor clarity increases, so does student mastery of content or skills with a concomitant improvement in lecturer evaluations.

Four constructs of instructor clarity continue to guide current studies: oral and written clarity, presentation clarity and process or organisational clarity (Wrench et al. 2009; Chesebro and Wanzer 2006). If lecturers aim to promote effective learning as their singular academic responsibility then they ought to be clear in how they convey an academic message (oral and written clarity), in the way they expound the content (content clarity) as well as the process they follow to present their content (process clarity). Forthwith, we elaborate on these constructs.

Instructor oral clarity (IOC) refers to how clearly instructors express themselves verbally which includes their grammatical proficiency and oral fluency in the medium of instruction (Daly and Brown 2007; Yilmaz 2011). In South Africa, although never assessed officially, lecturers are expected to be proficient in the language of teaching and learning (LOLT), which has increasingly become English even though not their mother-tongue, for many.

IOC is further manifested in the instructors' audibility (speech volume), the pace of their speech, the pitch, cadence and modulation of their teaching voice (Sidelinger and McCroskey 1997), as well as the frequency of surrogates i.e. hesitation or fillers like "uhs" and "ums" (Wrench et al. 2009). Hybels and Weaver (2012) warn that these speech mannerisms make it difficult to follow the speaker who also sounds uncertain, creating the perception that the speaker lacks confidence or content knowledge. IOC thus implies speaking in a manner which facilitates students' understanding the exposition of content, as well as receiving appropriate feedback after having asked a question (Simonds 1997).

Much as writing on a chalkboard or flip chart may seem outdated with instructional technology available in many lecture halls, writing is still known to support an oral message (exposition of content) with its visual reinforcement (Chesebro and Wanzer 2006). Instructor written clarity (IWC) thus refers to the clear, unambiguous formulation of task briefs and examination instructions as well as the creation of learning support materials as crucial academic forms of communication. For as Gibbs (2004) warns, students by their own efforts, 
can generally overcome their lecturers' poor teaching but they cannot do this when assessment tasks have been poorly formulated. In previous decades, IWC would have merely referred to the legibility and visibility of the instructor's handwriting on the board (Stefik et al. 1987; Moulton 1994). More recently instructors support student learning by providing them with detailed notes to review on-line, or offering skeletal outlines during instruction, which signal key ideas (Neef, McCord and Ferreri 2006; Theall 2005).

Several studies confirm that $21^{\text {st }}$ century students, even in developing contexts, are set to learn using sophisticated technology (Boyer, Briggeman and Norwood 2009; Crews et al. 2011; Trimble 2008). Various e-learning platforms, as well as mobile devices, interactive electronic white boards, educational applications, and social media, have added a new dimension to the criteria for clarity in terms of written texts (Duhaney 2000; Ebner and Nagler 2008). IWC therefore, could now also refer to the way in which text is set out on an electronic slide, guided by the $6 \times 6$ rule of no more than six words per sentence and only six sentences per slide (Evans 2015; Van Emden and Becker 2010). Not only the choice of font type and size but also the positioning of visual material contributes to meaning. A simple, consistent layout, used with a subtle colour to enhance the clarity of the message, with only a single idea per slide is thus desirable. (Ibid).

Instructor content clarity (ICC) is demonstrated by audible behaviours such as the lecturer explaining content, stressing significant concepts, clarifying meaning or responding to learners' lack of insight or understanding (Titsworth and Mazer 2010; Rodger, Murray and Cummins 2007; Simonds 1997). It also constitutes any means of reinforcing and expanding the academic message, or focusing the students' attention on fundamental notions and illuminating meaning (Hybels and Weaver 2012). ICC may be enhanced by introducing instructional material that appeals to both visual and auditory channels thus assisting students to grasp and internalise concepts (Wrench et al. 2009). Lecturers ought thus to be using mobile devices and multimedia platforms such as blogs, wikis, YouTube, and video clips to facilitate learner engagement (Ferreira 2006). Such materials create a sensory learning experience and support the mastery of new content, especially where students demonstrate limited proficiency in the medium of instruction (Hybels and Weaver 2012).

A lecturer's skill in formulating appropriate, strategic questions to purposefully and periodically prompt engagement with the content, elicit further questions and to probe student thinking also creates ICC and ought to initiate deep learning (Anderson 2002). Bowker (2010, 130) refers to a "question-centred pedagogy" and suggests that little research has been done on the manner in which and type of questions students ask. He argues that when students are required "to create their own questions about the course material [it] helps them to understand 
how the answers [that are accepted] are connected, contingent and contextual; and how they rely on, imply and beg additional questions".

Instructor process clarity (IPC) implies how logically the content of an instructional episode is structured. Lecturers might follow an instructor-directed approach, which includes: stating learning objectives and orientating students to the outcomes of the lecture; revising fundamentals; presenting new material; probing and checking for existing knowledge; creating conditions for independent practice; assessing progress and providing feedback (Anderson 2002). Reviewing key facts or procedures after an explanation provides learners with a further chance for grasping content, resolving misconceptions or improving dexterity. During this stage, students should also make associations, which help them to forge connections between themes or topics, shore up knowledge gaps, expedite the transfer of information, synthesise what has been learnt with the known thus eventually internalise meaning (Westwood 2004). Hybels and Weaver's study (2012) found that lecturers who were unclear, failed to capture their students' attention, which, in turn, mitigated against information retention. Previous studies (Westwood 2004; Comadena, Hunt and Simonds 2007; Evans 2006) have shown the importance of lecturers organising their content carefully to ensure high levels of clarity. Ribera et al. (2012) conducted a study at 38 universities in the United States, and found that lecturers who were considered to be clear during their instruction also measured higher levels of student engagement and more meaningful learning.

We, therefore, view lecturer clarity as the lecturer's ability to communicate content knowledge, orally, in writing; using various strategies and materials in such a manner, that student learning is optimised. It is against this background that we attempted to establish how university lecturers perceived their ability teach clearly, how their students perceived their instructional clarity and how the researchers validated these perceptions.

\section{METHOD OF INVESTIGATION}

The research was conducted at a South African university which offers diploma and degree qualifications, mainly via contact mode, on eight campuses, in four provinces across the country. We gathered both qualitative and quantitative data through a non-experimental mixed methods design for our once-off case study. Data were collected via questionnaires, interviews, and in-situ observations to illuminate the four aspects of lecturer clarity as discussed in the preceding literature review. We first gathered qualitative interview data using a non-probability, convenience sample of four black lecturers (one male and three females) and three white lecturers (one male and two females. Four lecturers were employed full-time and three, parttime. All seven lecturers held an appropriate teaching qualification and their experience in 
offering a basic communication skills course varied between six months and 15 years. They had all been lecturing for more than four years. Their ages were an inconsequential variable. Three protocols were developed with items selected from the Teacher Clarity Report (TCR) designed by Chesebro and McCroskey (1998). Data were triangulated by contrasting and comparing the data sets to produce valid conclusions (Ivankova, Creswell, and Plano Clark 2009).

A self-designed interview schedule guided our single 30-minute, face-to-face interview conducted in English and helped establish the perceptions the participants held of their own clarity while teaching. The interviews were transcribed using Dictate Express software and captured in the WEFT qualitative data analysis software. The transcripts were then studied to gain a broad sense of the lecturers' English language proficiency, matched against the video recordings. We argued that should there have been many grammatical slips, the more likely that misunderstandings could have occurred (De Jager and Evans 2013) and that inadequate oral proficiency in the LOLT would interfere with comprehensible input (Krashen and Brown 2007).

Next, in order to establish how the students perceived their lecturers' clarity, quantitative data were gathered through a single 30-minute, structured, paper-based, 5-point Likert scale questionnaire, administered by the primary researcher to the target lecturers' students at the close of the academic year. The questions were adapted from the Teacher Clarity Report and the extended version of the Teacher Clarity Measure by Sidelinger and McCroskey (1997), for the purpose of triangulating the data gleaned from the interviews. Two hundred and fifty-two first year students between the ages of 16 and 41 years returned their questionnaires. All the respondents self-identified as black with 43 per cent male students and 57 per cent female students completing the questionnaire survey. They were registered for different degree programmes in two faculties but were enrolled for the same communication skills course, taught by the participant lecturers. The scope of our study did not merit including students in all the faculties or from all campuses. These data sets were organised and captured in SPSS for later statistical analysis.

In addition, 60-minute classroom observations per lecturer were conducted by the primary researcher to establish how clear each lecturer was in a formal instructional context. A commercial software (eCOVE) - supported by video recordings - was used to record observable lecturer behaviours in chunks of five minutes during the course of the contact session. We focused on four areas that affect success in the classroom: instructor and student actions, specific individual or whole class incidents (Brown and Tenny 2004). The video recordings were scrutinised multiple times to crosscheck data obtained from the observations 
after which an electronic report with comments was generated for analysis.

We took into account that the behaviours the participants engaged in while being observed may have differed from that which they would have exhibited had they not knowingly been observed and video recorded. In order to minimise this "Hawthorne effect", we conducted multiple viewings looking for patterns and (in) consistencies in the lecturers' communicative behaviours. Finally, we also used the oral assessment scale of the International English Language Test System (IELTS), to rate the lecturers' English proficiency during the lectures that were video recorded. This instrument rates speakers' English proficiency in descriptive bands ranging from band 0 (non-English user) to band 9 (expert user) (https://www.teachers. cambridgeesol.org/ts/exams/academicandprofessional/ielts/speaking).

All ethical considerations were taken into account and formal clearance was secured at the research sites from the relevant gatekeepers as well as from all participants before data gathering began.

\section{DATA ANALYSIS AND DISCUSSION}

We had the assistance of a statistician, an independent critical reader and used member checking, to ensure that the study met the quality criteria and would be considered reliable and valid. We applied content analysis strategies to the qualitative data sets and inferential as well as statistical analyses for the quantitative data. A self-designed coding manual with predetermined codes was developed, which guided the analysis of the data obtained from the questionnaire and the classroom observations. The analyses sought to establish perceptions that lecturers and their students held of the participant lecturers' clarity during instruction. These perceptions were gauged against those that the primary researcher had formed during the classroom observations and we endeavoured to establish whether any variables relating to the lecturers' instructional clarity might possibly account for inadequate student throughput. The data sets were analysed separately and then collapsed to reveal the following:

\section{Perceptions: Lecturer oral clarity}

The interview transcripts permitted for a reasonable evaluation of the lecturers' spoken English proficiency as gauged using the IELTS scoring rubric. Of the seven participants, six lecturers were considered sufficiently proficient to offer instruction in English as they had made a limited number of excusable grammatical errors (L1 (0); L2 (1); L3 (5); L4 (2); L5 (3) and L6 (0)) placing them between bands six and nine (L5= Level 9, L2 = Level 7, L1, L3, L4 and L6 = Level 6). During the interviews and observations, Lecturer 7 had frequent pauses, repeated herself and appeared unsure as she spoke. She used basic sentence construction and a limited 
range of vocabulary. We also judged her proficiency problematic as the analysed chunk of oral data indicated 13 language errors, rating this participant's spoken English on band 4. This band is for someone who "could not respond without noticeable pauses and spoke slowly with frequent repetitions, was able to talk about familiar topics but could only convey basic meaning on unfamiliar topics, produced basic sentence forms and some correct simple sentences and used limited range of pronunciation features" (ibid).

This poor proficiency rating was also borne out by a student's comment that this lecturer “... sometimes uses Sepedi during an English lecture; this makes it harder to follow discussions". Sepedi is one of South Africa's eleven official languages but not an official medium of instruction at the research site. Some students complained about Lecturer 7's code switching. Such limited spoken proficiency in English raises concerns in terms of how effectively content is being expounded with the concomitant effect on learning.

Students' responses to item 13 of the questionnaire were underscored by the individual IELTS ratings. Students commented that their lecturers "speak[s] English fluently" and [their communication] is "articulate". Sixty-one per cent of the students felt they understood the instructional communication and offered phrases like “... [The lecturer] uses English that is understandable"; “... her English is straight forward” and "... uses plain and simple English which makes it easier for me to follow". One student stated, "I only have a problem with her accent. Sometimes she pronounces words in a unique way." We were uncertain how to interpret "Her English is too deep" - An apparently problematic communicative behaviour possibly obscuring meaning due to highfalutin English?

Seventy per cent of the students pointed out that their lecturers were always audible during instruction. The eCOVE reports on lecturers' oral clarity showed that five lecturers (L1, L2, L4, L5, and L6) were audible during the entire one-hour session while audibility was compromised when L3 read from lecture notes and L7 moved towards individual students during responses. Poor audibility has the potential to affect students' learning negatively as was found by Worley et al. (2007) who, in addition, warned that all students need to hear with absolute clarity or else they will disengage from the learning opportunity and lose out on key information, with negative implications on students' performance. Lecturers must adapt their instructional language accordingly.

Just over half the respondents $(56 \%)$ perceived their lecturers to provide appropriate and detailed answers clearly. Yet too often, lecturers did not respond with sufficient clarity as students repeatedly asked for more clarity in follow-up questions; one lecturer (L7) even leaving questions unanswered. Two lecturers (L3, L7) did not ask students any questions during their lectures. These unsatisfactory communicative behaviours imply that students were not 
supported in understanding connections or inter-related concepts and could thus not adequately contextualise the new content (Bowker 2010).

\section{Perceptions: Lecturer written clarity}

The lecturers perceived themselves as having written clarity but this view was not shared by students nor was it borne out by the observations. Two items established perceptions of lecturers' written clarity: the construction of tests and assignment instructions and information written on the white board or flip chart. Less than half (44\%) of the respondents felt that test questions had been formulated comprehensibly. When asked whether their students understood their written instructions and formulation of questions during tests and assignments, three lecturers replied confidently in the affirmative, two indicated that they thought on average, students understood their written instructions and the remaining two awkwardly hoped that the majority did. Later during the interviews, four lecturers acknowledged that some students battled to follow their instructions and that they often needed to rephrase and elucidate on each requirement of a task or assignment in class before the students could complete it on their own. Their explanation of such support strategies suggested their perception was that the students' English proficiency was poor, rather than a lacuna on their part.

Students felt that if lecturers provided a written scope for tests and compiled a memorandum, which could serve as feedback on assessments their academic performance would improve. During an observation, one lecturer discussed an assignment that had been assessed and returned to students. It was evident from their performance that they had misinterpreted the instructions but it remains unknown whether the lecturer had been unclear or whether the students' language proficiency was lacking as an analysis of written documents was not included in this study.

The eCOVE observation reports revealed that lecturers did not use the board often when teaching to explain content or demonstrate links as only 55 per cent of respondents reported such behaviour. Two (male) lecturers did not write on the board at all but read from and explained the texts held in their hands. Discussing such abstractions may have been enhanced by written explanations as established by Chesebro and Wanzer (2006). The video recordings indicated that all five female lecturers used the board at times to support their vocal message. Much as the lecturers claimed to use the written word in the form of handouts, overhead projection or electronic slide shows, only one lecturer used an electronic slide show, although unsuccessfully due to logistics. It is not clear why the lecturers did not use instructional materials or integrate technology into their instruction, since their lecturer halls were equipped with sophisticated technology. This needs to be pursued in further research. 


\section{Perceptions: Lecturer content clarity}

Observation data contradicted claims made by the lecturers during the interviews that they regularly used examples, detailed explanations and illustrations to clarify the content. Lecturers generally used "talk-tell" mode and relied to a limited degree on clarifying strategies. This behaviour was supported by questionnaire responses in which 59 per cent of the students stated that their lecturers used relevant examples, while 41 per cent indicated that lecturers used demonstrations or role-play. Lecturers repeated or stressed important points (54\%) while 52 per cent of the students perceived the lecturers to explain new concepts. These percentages suggest that - on average - lecturers were unable to make their content sufficiently clear to half the student cohort. One lecturer confessed that she never used support material claiming, "We do not have enough resources", a statement contradicted by her colleagues. Only a third (31\%) of the students specified that their lecturers implemented at least three types of learning support materials during instruction, implying that students were unnecessarily reliant on auditory measures during instruction.

Content clarity is also achieved by lecturers asking students different types of questions to guide them through the content. Lecturers claimed to vary their questioning techniques in order to assess understanding, to check or revise new content knowledge, to elicit opinions, and to capture factual and perceptual information. However, during observations, lecturers asked fewer than two lower order questions each, while others posed the same low-level questions more than once, as reflected in Figure 1.

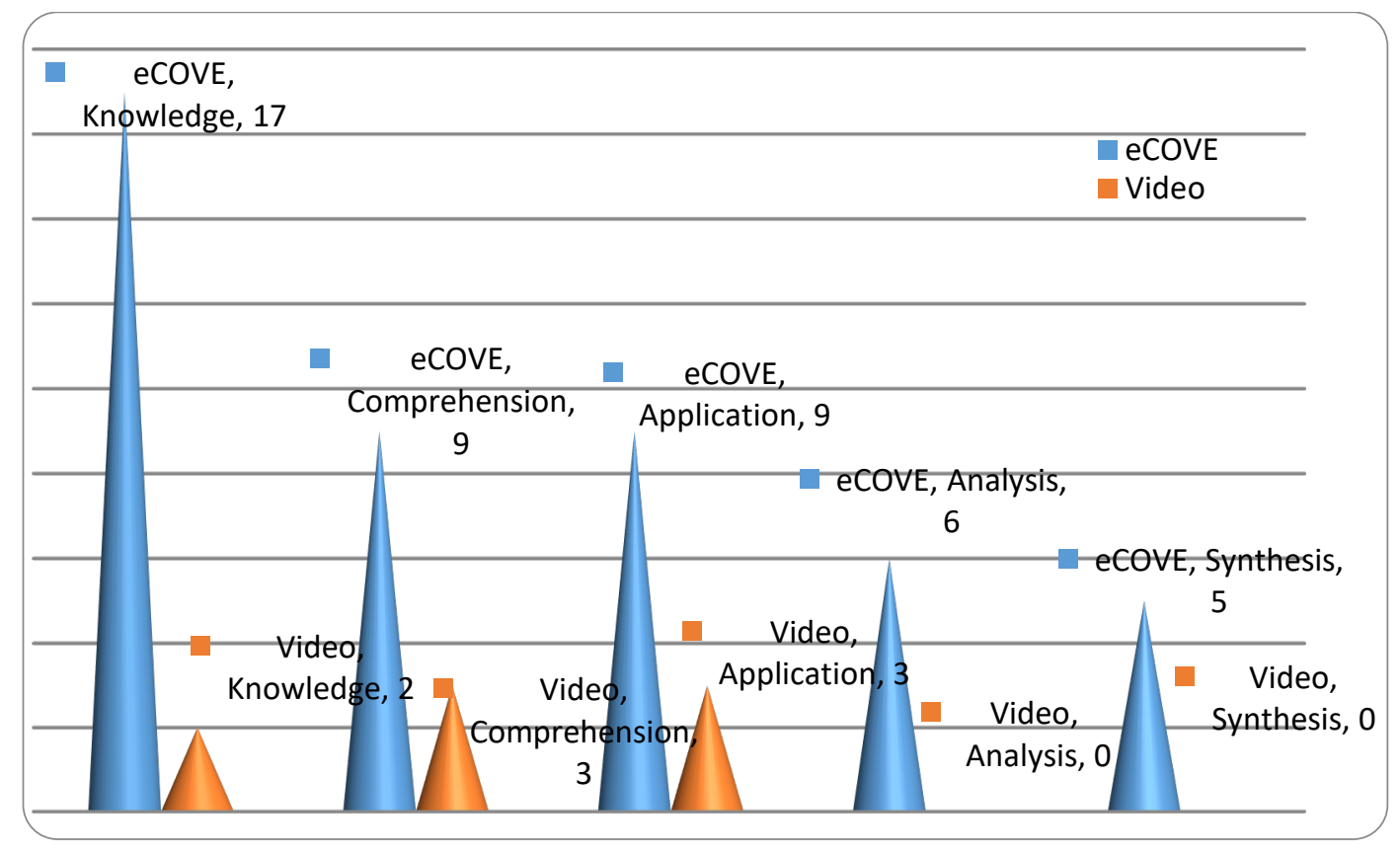

Figure 1: Frequency and levels of questions asked during instruction for all lecturers ( $n 7$ lecturers) 
Using the eCOVE observation software, we classified the type of questions lecturers asked: Elaboration (e.g. Can you expand on this?), Forced-association (e.g. How is ... like ...?), Non-divergent (Factual recall of statements), Pretend (e.g. If you could do anything to solve ...), Quantity (e.g. How many ...?), Reorganisation (e.g. what would happen if ...?) and Viewpoint (e.g. How would X feel about ...?). Five lecturers formulated more than two types of questions, as reflected in the Figure 2.

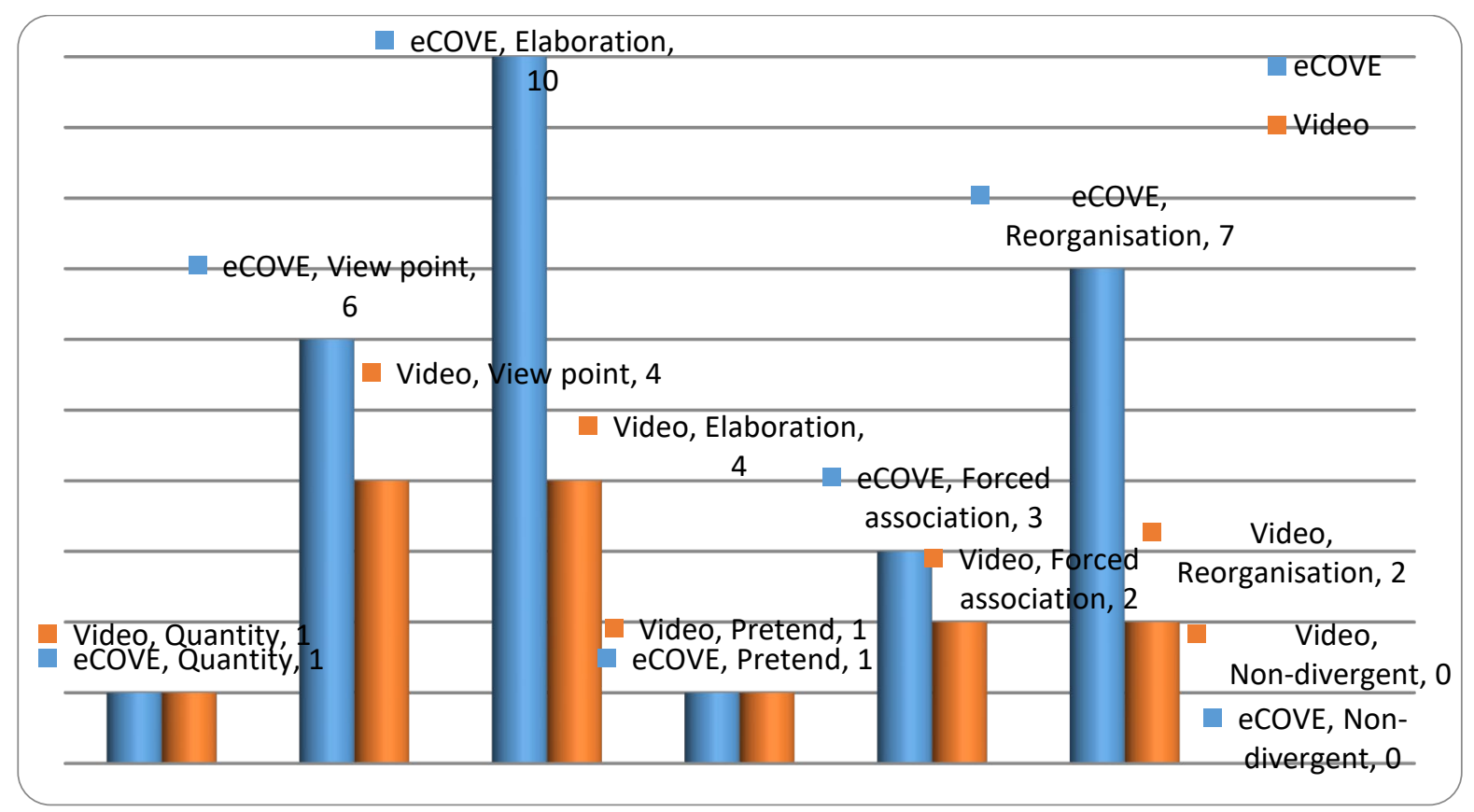

Figure 2: Frequency of the types of questions asked during instruction ( $n 7$ lecturers)

Much as the lecturers declared themselves academically well qualified and experienced enough to offer the communication course, they did not adequately vary the level or types of questions they asked nor did they 'question purposefully' which Erdogan and Campbell (2010) found helps to increase student engagement and fosters critical and creative thinking. Their unrefined questioning skills were ironic in the face of their appointment brief to train students to become effective communicators. Clear teaching helps students to take down more detailed class notes, improve on performance during assessments (Titsworth and Kiewra 2004) and attain deeper learning (Chesebro and McCroskey 2001).

\section{Perceptions: Lecturer process clarity}

During the interviews, all but one lecturer claimed to follow a traditional style of instruction as she put it, "Introduction, go into the lecture and then conclusion". Others could not specify the 
steps or sequence they followed during a lecture. One lecturer said, "I put the topic across, do a bit of research to find out where the students are and then move on from there". There was neither a logical sequence to their lecture nor a marked distinction between the preview, presentation and review phase. They launched straight into the topic of the day, delivered content and ended abruptly. Three lecturers had no introductory phase but launched straight into the presentation. The presentation stage was largely influenced by the aspects of the content the lecturers planned to deliver e.g. first discussing the format of the classified adverts, and then providing guidance in responding to a job advertisement. Just over half of the student respondents $(55 \%)$ perceived their lecturers to follow a logical, sequential (step-by-step) presentation while 59 per cent perceived their lecturers to stay on topic. Lack of process clarity was further evidenced by half the students $(50 \%)$ perceiving their lecturers to have set out the learning objectives at the start of the session while 39 per cent indicated that their lecturers drew on what students already knew to prepare them for the new content about to be explained. Fiftysix per cent of the respondents indicated that their lecturers presented them with practice tasks in order to consolidate what had been taught. The students' verbatim written comments endorsed the lack of process clarity stating that lecturers ought to; "use lecture time fully and not leave the class early", "explain the objectives of the lecture", "stay on the topic", "not take information as it is from the textbook" and to "add style" in their presentation. The observation reports support the students' perceptions as only one lecturer checked on students' prior knowledge before starting the lecture.

Lecturers' process clarity was further explored using the Distribution of Class Time tool, which showed how lecturers structured the 60 minutes available to them per lecture. It was apparent that none of the lecturers covered all the activities they had planned for the lectures. Video recordings confirmed that on average lecturers spent more time presenting content to the exclusion of assigning learning tasks, which ought to have augmented the explanations and engaged students at a cognitive level. There were either no class tasks (L2, L6, and L7) or where evidenced, such tasks were part of content presentation rather than extension or assessment of student learning (L1, L3, L4, and L5). All data sets provided evidence indicating that lecturers did not follow clear procedural patterns when presenting their content.

Throughout the analysis of data, Lecturer 7 signified as a problematic outlier. She was the least effective communicator, often making grammatical errors or switching to a vernacular not for the sake of the students' but due to her own inadequate fluency in English. Using a local language, which not everyone understood, excluded some students. When she did use the board, she wrote down passages from the textbook rather than an outline. She was also unclear in the way she presented the content; she did not highlight definitions or repeat key points nor did she 
use any instructional support material. She admitted to not following a step-by-step process when presenting her lectures. This poor lecturer clarity was painfully evident in the videorecorded observations and was confirmed by the students' forthright comments in the questionnaire.

In summary, our study showed that overall there was a mismatch between lecturers' own perceptions of their instructional clarity and that of their target audience. Lecturers, with one exception were proficient in the medium of instruction but their clarity in several key instructional variables was inadequate. Although we did not set out to statistically correlate lecturer clarity with student performance, the perceptions expressed by students and observed by us indicate the importance of lecturer clarity and imply the potential to affect student learning. It is thus probable that this problematic communicative behaviour on the part of lecturers may be contributing towards poor academic progress.

Although the focus of this study was on the lecturers, the language errors in the students' responses may have influenced how they received and processed communication from their lecturers. In addition, there is the possibility that first year students might not have been able to make accurate judgements about what might be expected of their lecturers. Further longitudinal research might exploit these limitations and solidify the relationship between lecturer clarity and its impact on student learning and resultant performance.

\section{CONCLUSION}

Apart from the tension that existed between the perceptions of lecturers' and their students', our study showed that proficiency in the medium of instruction is an insufficient criterion for lecturer clarity. Lecturers ought to be mindful of their clarity in all four spheres during instruction in order for their instructional skills not to be perceived negatively by students. Any instructional dissonance is cause for concern since clarity ought to be a universal attribute of effective instructors and cuts across disciplines and year levels. Institutions of higher education therefore, have the responsibility to quality assure lecturer oral proficiency in the medium of instruction and a lecturer's ability to structure and present content clearly using a variety of instructional strategies. Where necessary, lecturers ought to be supported by relevant interventions to enhance their teaching thus contributing to students' improved academic success and throughput.

\section{REFERENCES}

Anderson, L. W. 2002. Curricular alignment: A re-examination. Theory into Practice 41(4): 255-260.

Bowker, M. H. 2010. Teaching students to ask questions instead of answering them. Thought \& Action: 
127.

Boyer, T. A., B. C. Briggeman and F. B. Norwood. 2009. Demand for multimedia in the classroom. Journal of Agricultural and Applied Economics 41(3): 791-808.

Brown, C. and J. Tenny. 2004. Use of electronic observation tools: Improving classroom teacher effectiveness through data driven supervision. Society for Information Technology \& Teacher Education International Conference.

Bulger, S. M., D. J. Mohr and R. T. Wall. 2002. Stack the deck in favour of your students by using the four aces of effcetive teaching. Journal of Effective Teaching 5(2).

Chesebro, J. L. and J. C. McCroskey. 1998. The development of the Teacher Clarity Short Inventory (TCSI) to measure clear teaching in the classroom. Communication Research Reports 15(3): 262266.

Chesebro, J. L. and J. C. McCroskey. 2001. The relationship of teacher clarity and immediacy with student state receiver apprehension, affect, and cognitive learning. Communication Education 50(1): 59-68.

Chesebro, J. L. and M. B. Wanzer. 2006. Instructional message variable. In Handbook of instructional communication: Rhetorical and relational perspectives, ed. T. P. Mottet, V. P. Richmond and J. McCroskey. USA: Pearson education, Inc.

Collins, J. W. and N. P. O'Brien. 2003. The greenwood dictionary of education. Connecticut, US: Greenwood Press.

Comadena, M. E., S. K. Hunt and C. J. Simonds. 2007. The effects of teacher clarity, nonverbal immediacy and caring on student motivation, affective and cognitive learning. Communication Research Reports 24(3): 241-248.

Cosser, M. and M. Letseka. 2010. Introduction. In Student retention and graduate destination: Higher education and labour market access and sucess, ed. M. Letseka, M. Cosser, M. Breier and M. Visser. Cape town: Human Science Research Council.

Crews, T. B, L. Ducate, J. M. Rathel, K. N. Heid and S. T. Bishoff. 2011. Clickers in the classroom: Transforming students into active learners, 9.

Daly, A. and J. Brown. 2007. Lecturer communication in a multilcultural higher education context, in student success in international education. ISANA International Conference, Standford Grand, Australia, November

De Jager, L. and R. Evans. 2013. Misunderstanding during instructional communication as related to oral proficiency. Southern African Linguistics and Applied Language Studies 31(1): 97-110.

Duhaney, D. C. 2000. Technology and the educational process: Transforming classroom activities. International Journal of Instructional Media 27(1): 67-72.

Ebner, M. and W. Nagler. 2008. Has the end of chalkboard come? A survey about the limits of interactive pen displays in higher education. Proceeding of the 4th International Microlearning 2008 Conference on Microlearning and Capacity Building.

Erdogan, I. and T. Campbell. 2008. Teacher questioning and interaction patterns in classrooms facilitated with different levels of constructivist teaching practices. International Journal of Science Education 30(14): 1891-1914.

Evans, R. 2006. The impact of presenter speech personality on learner participation during televised instruction. Journal for Language Teaching/Tydskrif vir Taalonderrig 40(2): 21-34.

Evans, R. (Ed.). 2013. Communication, culture and the multilingual classroom. Pretoria: Van Schaik Publishers.

Ferreira, J. G. 2006. Effective mediation of learning through the use of media and everyday resources. In The educator as mediator of learning, ed. M. Nieman and R. Monyai. Pretoria: Van Schaik Publishers.

Finn, N. and P. Schrodt. 2012. Students' perceived understanding mediates the effects of teacher clarity and nonverbal immediacy on learner empowerment. Communication Education 61(2): 111-130. 
Fraser, W. and R. Killen. 2005. The perceptions of students and lecturers of some factors influencing academic performance at two South African universities. Perspectives in Education 23(1): 25-40.

Gayle, B. M., R. W. Preiss, N. Burrell and M. Allen. 2009. Classroom communication and instructional processes: Advances through meta-analysis. Routledge.

Gibbs, P. T. 2004. Trusting in the university: The contribution of temporality and trust to a praxis of learning. USA: Kluwer Academic Publishers.

Haskins, W. A. 2000. Ethos and pedagogical communication: Suggestions for enhancing credibility in the classroom. Current Issues in Education 3(4): 1-8.

Hybels, S. and R. L. Weaver. 2012. Communicating effectively. New York: McGraw-Hill Companies, Inc.

Ivankova, N. V., J. W. Creswell and V. L. Plano Clark. 2009. Foundations and approached to mixed methods research. In First steps in research, ed. K. Maree, 254-282. Pretoria: Van Schaik Publishers.

Krashen, S. and C. L. Brown. 2007. What is academic language proficiency. STETS Language \& Communication Review 6(1): 1-5.

Lewin, T. 2014. Student access and success: Issues and interventions in South African universities. Cape Town: Inyathelo: The South African Institute for Advancement.

MacGregor, K. 2009. South Africa: Shocking results from university tests. (0035). Accessed 30 October 2009.

McCroskey, J. C., K. M. Valencic and V. P. Richmond. 2004. Towards a general model of instructional communication. Communication Quarterly 52(3): 197-210.

Mothata, S., E. Lemmer, T. Mda, and F. Pretorius. 2000. A dictionary of South African education and training. Randburg, South Africa: Hodder \& Stoughton Education.

Moulton, J. 1994. How do teachers use textbooks and other print materials: A review of the literature. The Improving Educational Quality Project, South Africa.

Neef, N. A., B. E. McCord and S. J. Ferreri. 2006. Effects of guided notes versus completed notes during lectures on college students' quize performance Journal of Applied Behavior Analysis 39(1): 123130.

Ribera, T., A. Brekalorenz, E. R. Cole and T. F. N. Liard. 2012. Examining the importance of teacher clarity: Findings from the faculty survey of student engagement. Annual Meeting of the American Educational Research Association, Vancouver, BC, Canada, 13-17 April 2012.

Rodger, S., H. G. Murray and A. L. Cummins. 2007. Effects of teacher clarity and students anxiety and student outcomes. Teaching in Higher Education 12(1): 91-104.

Sidelinger, R. J. and J. C. McCroskey. 1997. Communication correlates of teacher clarity in the college classroom. Communication Research Reports 14(1): 1-10.

Simonds, C. J. 1997. Classroom understanding: An expanded notion of teacher clarity. Communication Research Reports 14(3): 279-290.

Stefik, M., G. Foster, D. G. Bobrow, K. Kahn, S. Lanning and L. Suchman. 1987. Beyond the chalkboard: Computer support for collaboration and problem solving in meetings. Communications of the ACM 30(1): 32-47.

Teven, J. J. and J. E. Herring. 2005. Teacher influence in the classroom: A preliminary investigation of perceived instructor power, credibility, and student satisfaction. Communication Research Reports 22(3): 235-246.

Theall, M. 2005. Explain course material clearly and concisely. POD-IDEA Center Notes. http://www.theideacenter.org/sites/default/files/Item10Formatted.pdf

Titsworth, B. S. and K. A. Kiewra. 2004. Spoken organizational lecture cues and students notetaking as facilitators of student learning. Contemporary Educational Psychology 29: 447-461.

Titsworth, S. and J. P. Mazer. 2010. Clarity in teaching and learning: Conundrums, consequences and 
opportunities. In The SAGE handbook of communication and instruction, ed. D. L. Fasset and J. T. Warren, 241-263. California: SAGE Publishers, Inc.

Toale, M. C. 2001. Teacher clarity and teacher misbehaviour: Relationships with students' affective learning and teacher credibility. DEd., College of Human Resource and Education, West Virginia University.

Trimble, C. S. 2008. Criteria for effective use of technology in the classroom: Identifying when technology should and should not be used. Marketing Management Association (MMA) Fall Educators Conference.

Van Emden, J. and L. Becker. 2010. Presentation skills for students. London:Palgrave MacMillan.

Westwood, P. 2004. Effective teaching to reduce educational failure. Australian Journal of Learning Disabilities 3(3): 4-12.

Wilson-Strydom, M. 2015. Access and success - Transition into and through higher education. 2nd Higher Education Summit Pretoria, 15-17 August 2015.

Worley, D., S. Titsworth, D. Worley and M. Cornett-DeVito. 2007. Instructional communication competence: Lessons learned from award-winning teachers. Communication Studies 58(2): 207222.

Wrench, J. S., R. V. Peck and J. Gorham. 2009. Communication, affect, and learning in the classroom. California, USA: Creative Commons.

Yilmaz, C. 2011. Teachers' perceptions of self-efficacy, English proficiency and instructional strategies. Social Behavior and Personality 39: 91-100. 